\title{
Logística de Transportes e Expansão da Produção de Soja no Centro Oeste
}

\section{Jonnathas Marques Pais ${ }^{1}$}

Mestrando do Programa de Pós-Graduação em Economia Aplicada da Universidade Federal de Ouro Preto (PPEA/UFOP)

Email: jonnathasmarques@hotmail.com

Carlos Eduardo da Gama Torres

Professor do Departamento de Economia e do Programa de Pós-Graduação em Economia Aplicada da Universidade Federal de Ouro Preto (PPEA/UFOP)

Email: carlosgt32@hotmail.com

Resumo: O presente trabalho aborda os custos relacionados à produção e logística da soja, no Brasil com destaque especial para a região Centro oeste. Dessa forma o enfoque desse trabalho consiste em discutir como a intensa utilização do modal rodoviário no Brasil onera o custo fora da fazenda, se configurando como uma desvantagem perante o principal concorrente nesse mercado, os Estados Unidos.

Palavras-chave: Soja; Custo de transporte; Rotas; Intermodalidade.

Abstract: The present work deals with the costs related to the production and logistics of soybeans, in Brazil with special emphasis on the Midwest region. Therefore, the focus of this work is to discuss how the intense use of road transport in Brazil overtax the cost off the farm, becoming a disadvantage towards the main competitor in this market, the United States.

Key words: Soybean; Transportation costs; Routes; Intermodality.

\footnotetext{
${ }^{1}$ O Autor agradece o apoio da Fundação de Amparo à Pesquisa de Minas Gerais.
} 


\section{INTRODUÇÃO}

Nos últimos anos, o complexo soja tornou-se o principal componente da pauta de exportações brasileira. O vigoroso crescimento na quantidade comercializada pelo país com o resto do mundo a partir do ano 2000 certamente é um fenômeno a ser estudado. Naquele ano foram embarcados pouco mais de 11 milhões de toneladas da oleaginosa in natura nos portos do Brasil. Até novembro de 2017 esse volume já superava as 65 milhões de toneladas, segundo dados do Ministério da Indústria, Comércio Exterior e Serviços (MDIC), se tornando também o produto agrícola exportado em maior volume pelo país.

A grande mudança ocorrida na quantidade comercializada da oleaginosa deixou expostas algumas deficiências do setor produtivo, com destaque para a fragilidade da infraestrutura existente, que não é capaz de promover o escoamento dessa carga de maneira eficiente até os portos. Essa situação torna-se mais complexa quando a produção da oleaginosa vai se interiorizando em um país de dimensões continentais como é o caso.

A trajetória da urbanização brasileira, sempre teve como característica marcante, a concentração populacional em regiões próximas à faixa litorânea, de forma que o grau de disponibilidade de infraestrutura acompanhou essa característica. No entanto, a partir do início dos anos 70, mediante o desenvolvimento de cultivares adaptados ao clima tropical aliado à condições excepcionais no mercado internacional com a cotação mais elevada da história da soja sendo alcançada, mesmo não existindo na região infraestrutura adequada para realizar a ligação necessária às outras partes do território, a produção da oleaginosa se expandiu pelo cerrado brasileiro.

A partir do evidenciado surto produtivo no novo milênio, ficou claro que a infraestrutura disponível na região Centro Oeste não estava preparada para movimentar de forma eficiente um volume cada vez maior para os portos. A partir disso, o que se verifica é uma grande ineficiência logística, sobretudo no transporte de volumes cada vez maiores da oleaginosa oriunda do cerrado para os portos, com a intensa utilização do modal rodoviário percorrendo longas distâncias, onerando sobremaneira o custo de comercialização. Considerando-se para efeito de comparação o exemplo dos Estados Unidos, tal país é o maior produtor de soja do mundo e também possui sua região de cultivo distante do litoral mas, utiliza-se intensamente da intermodalidade para o escoamento de sua produção para os portos, de maneira que o custo de transporte final verificado é substancialmente inferior ao brasileiro.

Dessa forma, o presente trabalho tem como objetivo geral compreender como a deficiência na oferta de infraestrutura de transporte, em especial no estado do Mato Grosso, onera e diminui a rentabilidade da atividade sojícola no Brasil. Para alcançar os objetivos propostos além dessa introdução na seção 1 iremos tecer um panorama da produção de soja no Brasil e no mundo e discutir os fatores que motivaram a expansão dessa cultura para a região Centro-oeste. Na seção 2 iremos destacar os custos logísticos referentes à produção no Brasil e notadamente no Centro oeste. Na seção 3 a guisa de conclusão iremos propor uma agenda de pesquisa para a área. 


\section{SEÇÃO 1 - EVOLUÇÃO RECENTE DA PRODUÇÃO DE SOJA NO BRASIL}

A atenção dedicada pelo Estado brasileiro à produção de soja acentuou-se a partir de 1975 com a criação do Centro Nacional de Pesquisa de Soja como uma das unidades da EMBRAPA, com sede em Londrina (PR) tendo como objetivo principal buscar a adaptação dos cultivares à regiões de baixas latitudes. Nesse contexto, até 1970 a cultura de soja estava confinada a latitudes acima de 30os sendo que atualmente é possível cultivá-la com eficiência na faixa compreendida de 34오 a $5^{\circ} \mathrm{N}$ (DALL'AGNOL, 2016).

A partir da adaptação do cultivo a regiões tropicais, o crescimento da produção, da área cultivada e da produtividade da soja na região centro oeste deu-se de maneira pronunciada devido a vários fatores, destacando-se:

A) A topografia plana da região que propicia a utilização de máquinas de maior porte possibilitando uma maior rentabilidade do capital investido em diversas tarefas tais como: preparo do solo, plantio e colheita;

B) a estabilidade dos níveis pluviométricos da região comparativamente à maior variabilidade quanto as chuvas na região sul;

C) a grande disponibilidade de terras, que após a redução da acidez através da calagem com adição de calcário, se tornaram produtivas;

D) o fato de grande parte dos produtores serem oriundos da região sul, onde já cultivavam a soja, os inseriu no cerrado com um bom nível econômico e tecnológico

(CAMPOS, 2012).

O gráfico 1 evidencia a intensa mudança no eixo produtivo da oleaginosa durante os anos 80. O cerrado brasileiro que ao final da década de 70 possuía uma pequena participação na produção nacional de soja na década de 90 alcançou uma participação aproximada à verificada na região sul.

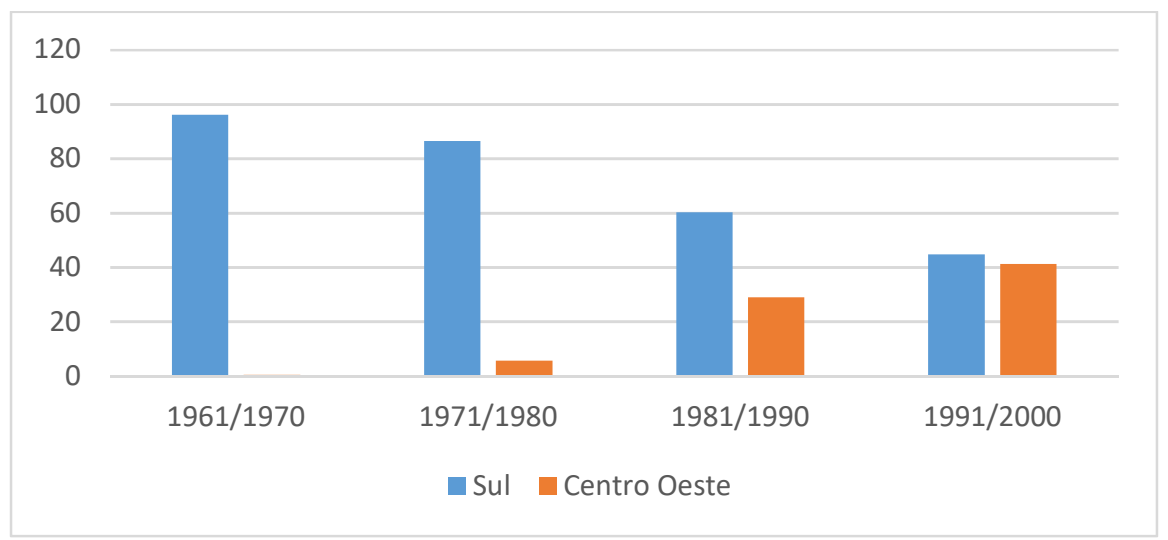

Gráfico 1 - Participação na produção brasileira de soja em \% Fonte: IBGE

O acelerado crescimento da produção de soja verificado no centro oeste ao longo da década de 80 contrasta-se com condições instáveis no Sul, principalmente devido a 
fatores climáticos, que prejudicaram o desempenho da tradicional região produtora. 0 crescimento da produção nacional, que alcançou uma média de 3\% ao ano durante os anos 80, deveu-se exclusivamente à expansão da oleaginosa no cerrado (PAULA et.al FILHO 1998).

Dados da pesquisa Produção Agrícola Municipal (PAM) do IBGE ainda mostram que a produtividade média verificada no centro oeste ao longo da década de 80 foi sensivelmente superior aquela registrada no sul ou, 1.867 e 1.617 toneladas/hectare respectivamente. Paralelamente a área cultivada no centro oeste aumentou mais de três vezes naquele período enquanto no sul a área cultivada manteve se sempre abaixo daquela verificada nos anos finais da década de 70 .

Durante os anos 90 aliado a um ganho substancial de produtividade nas principais regiões produtoras, a expansão da produção de soja apresentou um ritmo mais forte em relação aquele observado na década de 80 . No entanto, a dinâmica do crescimento produtivo aconteceu de maneira distinta entre as regiões Sul e Centro oeste, conforme destaca o gráfico 2. A área cultivada pela soja na região Sul manteve-se constante enquanto a região Centro oeste continuou apresentando um aumento da área cultivada. Cabe ressaltar que a região Centro oeste continuou apresentando produtividade superior aquela observada na região sul.

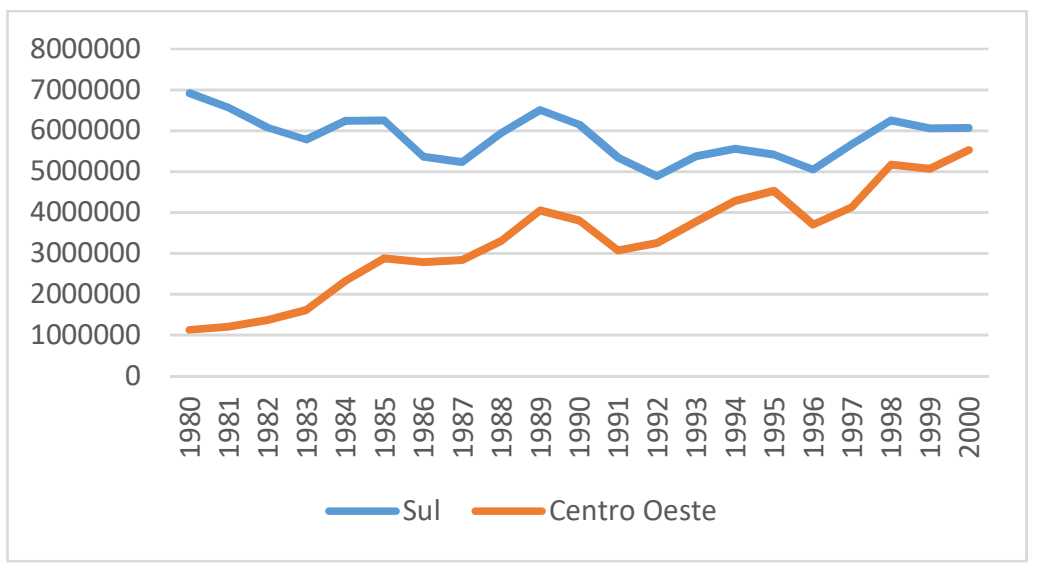

Gráfico 2 - Área cultivada em hectares

Fonte: IBGE

A partir de meados dos anos 80 devido à crise financeira que o país então atravessava, o incentivo estatal dado a agricultura por meio do crédito agrícola subsidiado cessou. No entanto, percebeu-se de maneira concomitante à escassez de crédito um intenso avanço tecnológico, evidenciando um dinamismo no setor orientado pelo setor privado (CAMPOS, et.al PAULA, 2002).

Essa agricultura de caráter empresarial, também conhecida como agronegócio, desenvolveu-se no Brasil tendo como expoente a produção da soja. A trajetória da soja se confunde com a própria história de modernização da agricultura brasileira. Seu sucesso fomentou discussões e ações antes inexistentes como desenvolvimento em pesquisa e tecnologia, modernização do setor agroindustrial e integração da cadeia produtiva. A revolução no modo produtivo, que posteriormente transbordou para outros cultivos incluiu a mecanização do plantio, investimento em estruturas de armazenagem, 
processamento, e expansão da fronteira agrícola por regiões antes praticamente selvagens como o Centro oeste. A cultura da soja foi também responsável pela modernização na gestão administrativa de produtores, fornecedores de insumos e processadores de matéria prima, inserindo nestes agentes econômicos uma visão empresarial que propiciou maior autonomia ao setor agrícola nacional (BRUM et.al HECK, LEMES, MULLER, 2005).

O sucesso da soja no Brasil foi responsável direto pela prosperidade da produção de carnes, que atualmente figura entre os principais produtos da pauta de exportações do país (DALL'AGNOL,2016). No fim dos anos 90 a soja começa a se consolidar também no nordeste e norte, dando início a uma nova região produtora que ficaria conhecida mais tarde por Matopiba, que são as iniciais dos estados que a compreende: Maranhão, Tocantins, Piauí e Bahia.

A partir dos anos 2000, o crescimento da produção de soja voltou a apresentar ritmo bastante elevado, conforme o gráfico 3. Nesse contexto a oferta nacional praticamente triplicou entre 2000 e 2015 . Foi nesse período que a região centro oeste se consolidou como a principal produtora de soja, com grande destaque para o estado de Mato Grosso que se tornou o maior produtor entre as unidades da federação, conforme o gráfico 3.

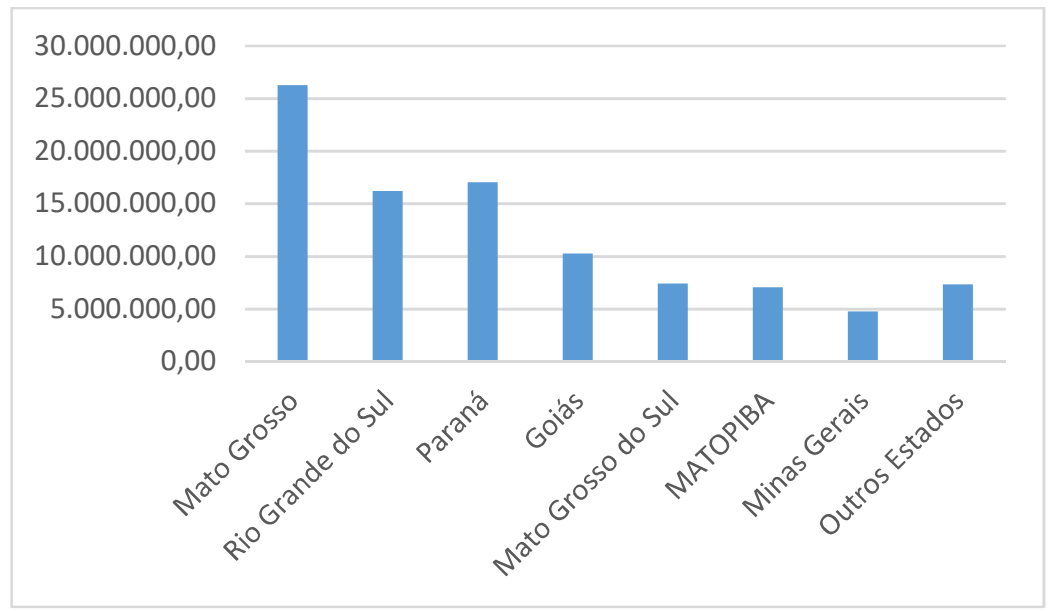

Gráfico 3 - Produção de soja em toneladas no ano de 2016 Fonte: IBGE

A entrada da China no comércio internacional da oleaginosa a partir do final dos anos 90 foi determinante para o crescimento deste setor econômico. No ano 2000 a China importou cerca de 10,1 milhões de toneladas de soja, em 2016 esse volume já ultrapassava 83,2 milhões de toneladas segundo dados do PSD Online do USDA. A China tem como característica ser demandante do grão de soja em seu estado natural, isso devido ao fato de possuir um imenso tecido industrial de processamento em seu território (HIRAKURI, 2014). Neste contexto ocorreu uma mudança significativa na participação relativa nas exportações brasileiras do complexo soja. Os produtos manufaturados, sobretudo o farelo, que ao longo dos anos 80 e 90 representavam o principal produto exportado do complexo soja, perdem importância relativa frente ao grão. Assim, o volume exportado de soja em grão pelo Brasil saltou de 11,7 milhões em 
2000 para 64,1 milhões em 2016 (USDA). Em 2013, pela primeira vez na história a quantidade do grão de soja exportada ultrapassa o consumo doméstico, processamento na indústria ou uso direto como alimentação animal.

Considerando-se a safra 2015/16, a participação de Estados Unidos, Brasil e Argentina corresponderam a aproximadamente 34\%, 31\% e 18\%, da produção mundial respectivamente. A Argentina, que possui calendário agrícola semelhante ao do sul do Brasil, apesar da grande produção, não se configura como um grande exportador da soja in natura, uma vez que suas exportações do complexo soja estão pautadas nos produtos derivados, farelo e óleo, consumindo em seu tecido industrial a maior parte da soja produzida no país. Dessa forma, Estados Unidos e Brasil foram responsáveis por 80,96\% do volume mundial de soja em grão exportada na campanha 2015/2016, segundo dados do USDA.

Pelo lado da demanda, a China configura-se como a grande importadora mundial do grão de soja, tendo sido naquele momento o destino de $62,42 \%$ do volume mundial importado. Apesar do país ter alcançado a quarta maior produção de soja no mundo, 11,75 milhões de toneladas na safra 2015/2016, o consumo doméstico é imensamente superior a produção, fazendo da China um importador líquido conforme gráfico 4.

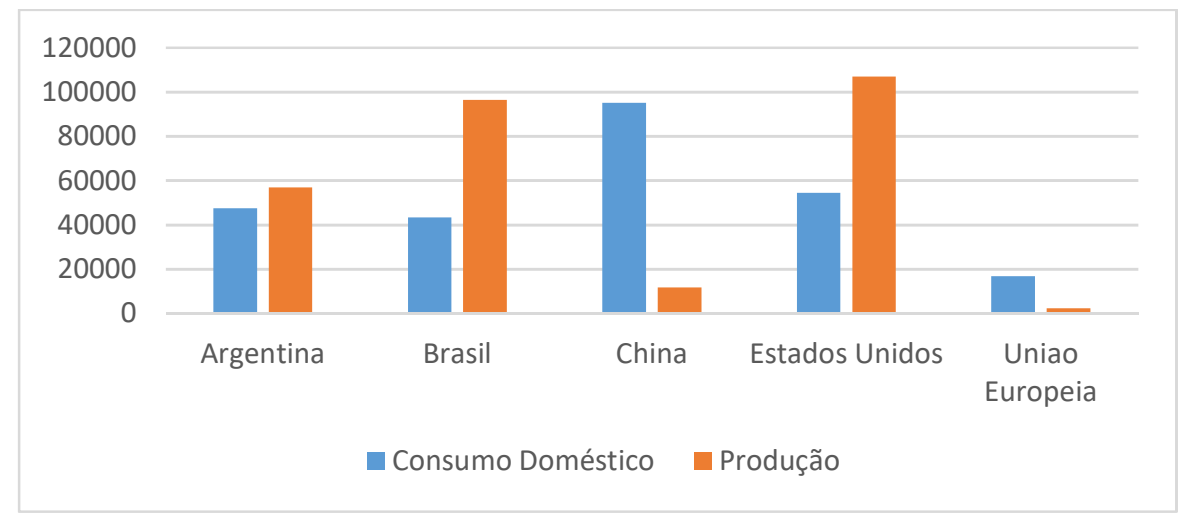

Gráfico 4 - Produção x Consumo doméstico grão de soja em mil toneladas Fonte: USDA

\section{SEÇÃO 2 - LOGÍSTICA DA SOJA NO BRASIL}

Apesar da evidenciada prosperidade no mercado da soja, com volumes cada vez maiores sendo exportados e processados, conforme discutido na seção 1, existem também sérias fragilidades estruturais que comprometem a competitividade internacional da oleaginosa brasileira. A alegada mudança espacial com a interiorização da produção de soja que aconteceu nos últimos 40 anos, não trouxe consigo apenas as destacadas vantagens naturais da região centro oeste uma vez que se tornou cada vez mais evidente a limitação da infraestrutura do país para realizar o escoamento eficiente de sua produção, aumentando assim o custo logístico e diminuindo a rentabilidade da atividade (HIJAR, 2004). 
Segundo Costa (2007 apud KUSSANO; BATALHA, 2012, p. 3) o custo logístico é definido como a soma do custo de armazenagem e movimentação de materiais (custo de transporte incluindo todos os modais e as operações de transbordo intermodal), custo da administração, custo de embalagem para a movimentação, custo tributário, custos de inventário. No entanto existe certa dificuldade para a definição de uma fórmula de custo logístico que seja universal, sendo mais indicado analisa-lo pela ótica das especificidades do produto.

Nesse caso, a soja, como a maioria das commodities agrícolas, possui um baixo valor agregado, além disso, a oleaginosa é um dos produtos com maior volume exportado pelo Brasil nos últimos anos. Somente na safra 2015/2016 mais de 54 milhões de toneladas saíram do país, segundo dados do MDIC. O volume e o valor agregado de um produto são características determinantes para a adequação de uma logística eficiente. Produtos que possuem baixo valor agregado e são transacionados em grandes volumes, demandam um sistema logístico de alta capacidade e com baixo custo unitário, mesmo que esse sistema incorra em um maior prazo de entrega (FLEURY, 2005).

Outras propriedades da oleaginosa são importantes para compreender quais são as necessidades para se lograr a otimização de custos logísticos. A soja é uma lavoura temporária, marcada por forte sazonalidade. A safra brasileira acontece na entressafra norte americana, ou seja, a colheita no Brasil é feita no primeiro semestre do ano, enquanto nos Estados Unidos a colheita é realizada no segundo semestre (IMEA, 2015). Dada essa característica natural, o escoamento de soja brasileira deve ser preferencialmente realizado no primeiro semestre, antes da safra norte americana. $O$ armazenamento da soja com finalidade de diluir o escoamento ao longo do ano, não é recomendável pelo comportamento da oferta no segundo semestre. Esse fator acaba pressionando ainda mais a frágil infraestrutura brasileira, onerando o custo logístico (HIJAR, 2004). O padrão sazonal da exportação da soja é bem definido: o pico acontece durante os meses abril, maio e junho, sendo que os meses de novembro, dezembro e janeiro representam os vales ao longo da trajetória.

Segundo o IMEA (2015), a Bolsa de Mercadorias de Chicago (CBOT) dita atualmente o padrão global de preços para a soja, uma vez que a existência de uma alta concentração de vendedores e compradores dos principais países faz com que os preços mundiais sejam balizados pela cotação praticada em Chicago. Atuando em um cenário como tomadora de preços no mercado externo, as empresas que atuam no mercado da soja no Brasil necessitam da manutenção de baixos custos para ganhar competitividade e não ter reduzido seu valor recebido (HIJAR, 2004).

Segundo Salin (2014) as fazendas brasileiras são mais eficientes quanto aos custos internos quando comparada as norte americanas, no entanto, a debilidade da infraestrutura brasileira, oneram os custos fora da fazenda de forma que o produto ao chegar em seu destino possua um custo final mais elevado em relação a soja produzida nos Estados Unidos.

Como a soja precisa percorrer longas distâncias até os portos de exportação, tanto no Brasil (notadamente no Centro Oeste), quanto nos Estados Unidos, o custo de transporte torna-se um elemento decisivo nesse mercado. Nessa fase, em que 
rotineiramente, recordes de volumes de soja exportados são alcançados anualmente, várias fragilidades de nossa infraestrutura ficam evidenciadas entre elas podemos destacar:

A) As condições precárias das rodovias;

B) A baixa capilaridade do sistema ferroviário;

C) O baixo aproveitamento do potencial hidroviário;

D) O excesso de burocracia e a baixa capacidade dos portos que geram como consequência a formação de longas filas de espera de caminhões para descarga da mercadoria e de navios para atracar.

Esse quadro acaba por implicar no descumprimento do prazo de entrega, acarretando multas que ainda oneram mais o custo logístico (FLEURY, 2005).

Tabela 1 - Densidade da infraestrutura em 2015

( $\mathrm{km}$ de infraestrutura por $1000 \mathrm{~km}^{2}$ de área)

\begin{tabular}{l|c|c|c}
\hline País & Rodovias & Ferrovias & Hidrovias \\
\hline Argentina & 25 & 13,3 & 4 \\
\hline Brasil & 25 & 3,4 & 2,6 \\
\hline Estados Unidos & 438,1 & 22,9 & 4,2 \\
\hline
\end{tabular}

Fonte: CNT, CIA, IBGE e DNIT*

Os modais de transporte mais adequados ao transporte de acordo com as propriedades citadas da soja in natura, isto é, alto volume e baixo valor agregado são o hidroviário e ferroviário. A função do modal rodoviário nesse caso seria atuar nas pontas, levando os grãos até o terminal mais próximo de um modal mais eficiente (hidroviário ou ferroviário). No entanto, o Brasil, apesar de ser um país de dimensões continentais, é caracterizado pela forte predominância das rodovias frente aos outros modais. Esse panorama vem se caracterizando desde a segunda metade do século XX e se configura como uma peculiaridade do Brasil frente a outros países com as mesmas dimensões territoriais, como China, Rússia e Austrália (HIJJAR, 2004). Ao compararmos a densidade da infraestrutura existente no Brasil com principais concorrentes no mercado internacional da oleaginosa, a diferença fica evidenciada, como podemos ver na tabela 1.

O caso da Argentina, terceiro maior produtor da soja, possui uma particularidade importante, pois a sua região produtora se localiza relativamente próxima à costa litorânea, com destaque para a província de Buenos Aires. Nesse contexto, a distância média até os portos é de 250 a $300 \mathrm{~km}$, diminuindo a importância relativa da eficiência do transporte frente aos outros concorrentes (IMEA, 2015). Além do mais, deve-se lembrar que o território da Argentina é relativamente menor que o dos outros produtores da oleaginosa, cerca de três vezes menor que Brasil ou Estados Unidos. Sendo assim quando analisamos a matriz de transporte da soja na tabela 2, podemos notar que apesar do escoamento da soja argentina ser realizado predominantemente pelo modal 
p. 29 - Logística de Transportes e Expansão da Produção de Soja no Centro Oeste

rodoviário, a curta distância ser vencida até o destino final, faz com que a opção por rodovias seja mais viável.

Tabela 2 - Participação em \% do modal de transporte na movimentação de soja em grão

\begin{tabular}{l|c|c|c|c|c}
\hline Modalidade & Argentina & \multicolumn{2}{|l|}{ Brasil* } & Estados Unidos & Exportação \\
\hline \multirow{2}{*}{ Rodoviário } & \multirow{2}{*}{ Doméstico } & Exportação & Doméstico & 29,0 \\
\cline { 3 - 6 } & 84,0 & 100 & 47,6 & 83,0 & 29,0 \\
\hline Ferroviário & 13,0 & 0 & 42,1 & 14,0 & 42,0 \\
\hline Hidroviário & 3,0 & 0 & 10,3 & 3,0 & $+/-1000$ \\
\hline
\end{tabular}

*Dados do Brasil se referem a 2016, os demais se referem a 2013.

Fonte: Elaborado pelo autor com base nos dados da ANTT, CNT, USDA

A movimentação da soja, após a colheita nas lavouras até os portos no Brasil e nos Estados Unidos é feita a longas distâncias, nesse momento a diferença de eficiência em custo de transporte entre os dois países começa a ser evidenciada. Considerando o período compreendido entre 2009 e 2013 nos Estados Unidos 37\% do volume total exportado foi transportado por ferrovias, $49 \%$ por hidrovias e apenas $14 \%$ por rodovias. Considerando-se o Brasil entre 2013 e 2016, os dados do anuário estatístico dos transportes da ANTT indicam que $47,05 \%$ do volume total de soja foi transportado por rodovias, 43,28\% por ferrovias e 9,67\% por hidrovias. É importante destacar ainda que a participação das rodovias no caso do transporte de soja para exportação nos portos do Brasil aumentou conforme o gráfico 5 indica.

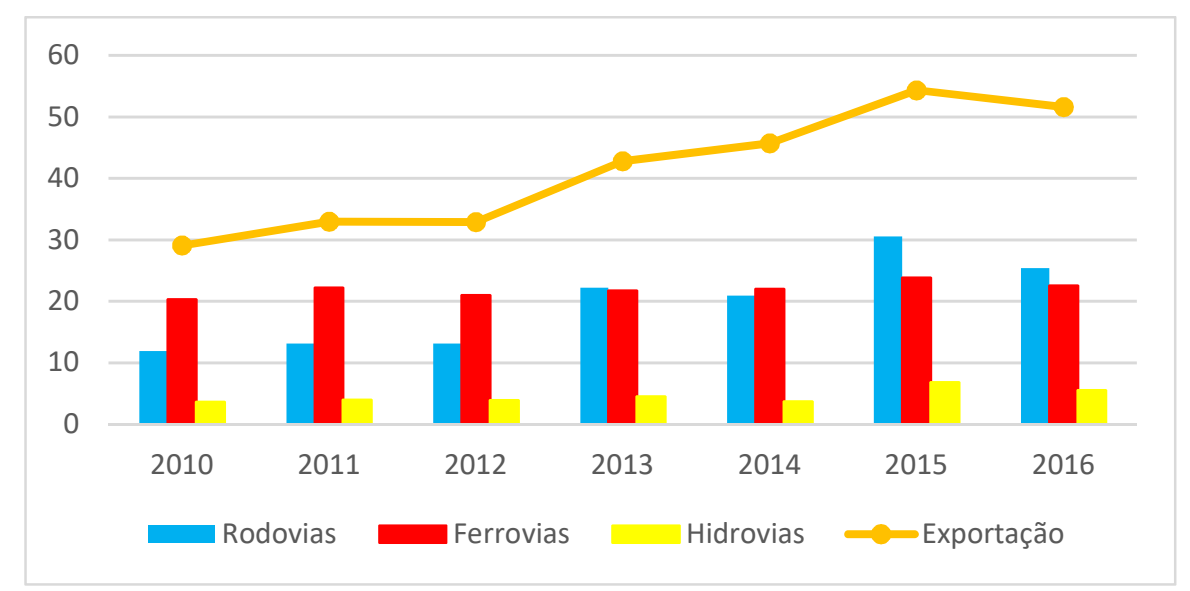

Gráfico 5 - Transporte de soja por modal para instalação portuária em toneladas Fonte: Elaborado pelo autor a partir de dados do MTPA, MDIC

O aumento do volume transportado pelas rodovias com destino aos portos coincide com o crescimento superior à 77\% verificado nas exportações entre 2010 e 2016. Enquanto o volume transportado por rodovias dobrou nesse período o transporte 
por ferrovias se manteve relativamente constante. Por meio do gráfico 5 pode-se notar também, o aumento no volume transportado por hidrovias, mesmo que esse seja o modal menos utilizado.

Neste contexto a opção pela utilização do modal rodoviário implica em uma série de externalidades negativas para a sociedade. Conforme (HIJJAR, 2004) um caminhão possui uma capacidade 150 vezes menor do que um comboio ferroviário e 600 vezes menor comparativamente a um comboio de barcaças. Considerando a mesma distância e carga, o modal ferroviário consome quatro vezes menos combustível em relação ao modal rodoviário. Paralelamente um conjunto de barcaças consome a metade observada a um comboio ferroviário (COSTA, 2008). Podemos destacar ainda que a taxa de acidentes verificada no transporte pelos modais ferroviário e hidroviário é significativamente menor do que aquela observada no transporte rodoviário (HIJJAR,2004). Paralelamente a utilização do modal rodoviário implica em maiores emissões de gases poluentes.

Aliado a grande participação do modal rodoviário na matriz de transporte do complexo soja deve-se destacar que o mal estado de conservação das rodovias brasileiras acaba ampliando o problema. Nesse contexto, devido às más condições das estradas, um caminhão pode ter sua velocidade média reduzida de $50 \mathrm{~km} / \mathrm{h}$ para $20 \mathrm{~km} / \mathrm{h}$ quando comparado a uma estrada em boas condições. A má conservação das estradas também aumenta o consumo de combustível, pneus e lubrificantes e manutenção em geral. Paralelamente, durante a época da safra, as estradas ficam congestionadas, principalmente nas rotas para os principais portos (COSTA, 2008).

A situação dos portos também torna-se um complicador na logística de escoamento da soja. A complexa regulamentação existente conjuntamente com uma estrutura portuária obsoleta e de reduzida capacidade de movimentação faz com que se formem filas de caminhões, navios e trens, onerando os custos (FLEURY, 2005). No primeiro semestre, durante a safra de 2004, navios chegaram a aguardar 60 dias para atracar e as filas de caminhões para desembarcar a mercadoria chegou a $120 \mathrm{~km}$ (HIJJAR,2004). A situação se torna ainda mais complexa à medida que existe uma concentração do escoamento em alguns portos das regiões sul e sudeste, mesmo para grãos oriundos de regiões como o centro oeste, que por sua geografia poderia escoar sua produção pelos portos do norte, mas devido a inexistência de infraestrutura adequada para movimentar a carga até aqueles portos, e até mesmo pela baixa capacidade estrutural destes, acabando enviando a maior parte de sua produção para os portos do sudeste e sul (CORREA; RAMOS; 2010).

No que se refere a estocagem do produto, a função dos armazéns é garantir a qualidade, principalmente em relação ao controle da umidade, reduzir perdas e estocar a produção excedente. Ao contrário dos Estados Unidos onde existe a predominância de armazéns particulares dentro das propriedades rurais facilitando o maior controle sobre - fluxo e qualidade por parte dos produtores, no Brasil esse tipo de estrutura corresponde apenas a 13,5\% do total dos armazéns e geralmente são concentrados apenas em grandes produtores. Esse panorama, deixa os pequenos e médios produtores com apenas duas opções: utilizam armazéns de terceiros, arcando com os custos, ou fazem o escoamento imediatamente após a colheita. Além do mais, atual capacidade 
estática é considerada insuficiente, nesse contexto podemos afirmar que a estrutura de armazenagem existente contribui com a concentração do escoamento no período da safra (PONTES et al. 2009; CNT, 2015).

O Brasil produziu mais de 96 milhões toneladas de soja na campanha de comercialização 2015/2016, de modo que o consumo doméstico foi superior a 43 milhões de toneladas e as exportações ultrapassaram os 54 milhões, conforme consulta aos dados do sistema PSD Online disponibilizados no site do USDA. Atualmente a região Centro oeste é a principal produtora de soja no Brasil, sendo que ao longo do ano de 2016 a sua produção ultrapassou os 44 milhões de toneladas. O grande destaque é o estado do Mato Grosso, que naquele mesmo ano contribuiu com um volume superior a 26 milhões de toneladas, sendo a principal unidade federativa na produção da oleaginosa. A região sul, histórica produtora, também segue uma trajetória de produção ascedente nos últimos anos, com um montante superior a 35 milhões de toneladas em 2016. Os estados do Paraná e Rio Grande do Sul possuem parcelas semelhantes dentro desse total, com leve vantagem para os paranaenses. O estado de Santa Catarina possui uma produção em menor escala, representando apenas cerca de $6 \%$ da produção total. A nova região de expansão, conhecida por Matopiba, registrou em 2016 uma produção inferior ao Mato Grosso do Sul, o motivo foi uma quebra da safra devido a problemas climáticos na região (TAVARES, 2016).

A região Centro oeste é a que mais sofre impactos negativos em relação a ineficiência da infraestrutura disponível. Dentre os principais problemas destacamos:

a) a pequena extensão e a má conservação da malha existente;

b) a grande utilização do modal rodoviário na matriz de transportes, não indicado dado o volume movimentado pela região e a sua distância até os portos e principais centros consumidores no país;

c) pouco uso uso da intermodalidade;

d) a baixa disponibilidade de armazéns nas propriedades rurais (TAVARES, 2016).

Tabela 3 - Densidade de rodovias ( $\mathrm{km}$ de infraestrutura / $1000 \mathrm{~km}^{2}$ de área)

\begin{tabular}{l|c|c}
\hline UF/ Região & Rede pavimentada & $\begin{array}{l}\text { Rede total (pavimentada + não } \\
\text { pavimentada) }\end{array}$ \\
\hline Distrito Federal & 157,09 & 281,52 \\
\hline Goiás & 37,52 & 284,13 \\
\hline Mato Grosso & 9,40 & 46,55 \\
\hline Mato Grosso do Sul & 22,35 & 182,65 \\
\hline Região Centro Oeste & 18,76 & 127,96 \\
\hline Paraná & 98,25 & 590,16 \\
\hline Santa Catarina & 73,70 & 640,66 \\
\hline Rio Grande do Sul & 40,31 & 536,39 \\
\hline Região Sul & 65,87 & 127,96 \\
\hline Fonte: SNV 2015 & &
\end{tabular}

A região Centro oeste possui uma das mais baixas densidades rodoviária do país, ficando a frente apenas da região norte. Paralelamente, em 2015, dados do Sistema 
Nacional de Viação (SNV), apontavam que apenas $16 \%$ das rodovias existentes no Centro oeste encontravam-se pavimentadas. Neste contexto o Mato Grosso destaca-se negativamente por apresentar a menor disponibilidade de infraestrutura rodoviária quando comparado as outras unidades da federação nas regiões Centro oeste e Sul, conforme tabela 3. Acentuando-se o quadro deficitário da infraestrutura de transporte rodoviário, entre os estados da região, o Mato Grosso é o que apresentou mais deficiências em sua malha rodoviária, segundo a "Pesquisa CNT de Rodovias" (2016). Segundo a referida pesquisa $61,9 \%$ das rodovias analisadas no estado foram classificadas como ruins ou péssimas.

As principais rodovias utilizadas para o escoamento da soja do Mato Grosso para exportação são a BR-163 que liga o Pará ao Rio Grande do Sul e a BR-364 que vai de Limeira (SP) até Rodrigues Alves (AC). Essas vias são utilizadas principalmente para escoar soja para os portos de Paranaguá e Santos respectivamente (CORREA, 2010). Segundo a pesquisa CNT de rodovias 2016, a BR-163 no Mato Grosso foi classificada como regular sendo que apenas um pequeno trecho entre os municípios de Nobres e Rosário do Oeste se encontra duplicado atualmente. O pavimento dessa rodovia foi classificado como bom em uma escala que vai até ótimo. Pode se destacar ainda o fato, da maior extensão da BR 163 não possuir acostamento. A BR 163 poderia ser utilizada para o escoamento da soja do Mato Grosso pelos portos do Norte, em especial no estado do Pará.

Os portos do arco norte possuem potencial para se tornar o principal ponto de escoamento da produção do cerrado, em especial do Mato Grosso, no entanto, é no trecho compreendido entre o norte do Mato Grosso e Santarém que a BR-163 se encontra em pior estado de conservação, sendo que grande parte desse trajeto não é sequer pavimentado. O clima equatorial da região, com altos índices pluviométricos, piora ainda mais as condições de tráfego. Existem registros de caminhões parados durante mais de uma semana nesse trecho devido a atoleiros. Esse panorama onera fortemente os custos de transporte incorridos ao se percorrer essa rota e acaba por direcionar os fluxos de soja aos portos mais distantes.

Apesar da situação descrita acima, o percentual da produção do Mato Grosso que escoada pelos portos do arco norte, em especial o de Barcarena (PA), tem aumentado conforme tabela 4. Na última safra o complexo portuário de Barcarena foi responsável pelo escoamento de 19,38\% da soja exportada por Mato Grosso, ficando atrás apenas do porto de Santos em representatividade. Ao se analisar em conjunto a participação dos portos do arco norte (Barcarena, Itacoatiara, Santarém e São Luís) nas exportações de soja do Mato Grosso na safra 2017 observou-se um percentual de 42,66\%. A tendência de aumento fica evidenciando ao se comparar com a safra de cinco anos antes (2012), quando essa participação estava em 17,43\%. 
p. 33 - Logística de Transportes e Expansão da Produção de Soja no Centro Oeste

Tabela 4 - Participação Percentual dos portos no escoamento de soja para exportação do Centro Oeste entre 2013 e 2017 (\%)

\begin{tabular}{|c|c|c|c|c|c|c|}
\hline UF & \begin{tabular}{|lll} 
Porto (UF do \\
porto)
\end{tabular} & 2013 & 2014 & 2015 & 2016 & 2017 \\
\hline \multirow{9}{*}{ MT } & Santos (SP) & 57,98 & 50,66 & 44,76 & 46,96 & 46,75 \\
\hline & Barcarena (PA) & - & 4,40 & 11,13 & 11,91 & 19,38 \\
\hline & Itacoatiara (AM) & 7,70 & 6,42 & 7,81 & 9,43 & 8,79 \\
\hline & Santarém (PA) & 5,37 & 4,33 & 4,23 & 8,21 & 7,09 \\
\hline & São Luís (MA) & 4,36 & 3,56 & 7,08 & 8,68 & 7,40 \\
\hline & $\begin{array}{l}\text { São Francisco do } \\
\text { Sul (SC) }\end{array}$ & 4,49 & 5,34 & 4,21 & 2,85 & 1,26 \\
\hline & Paranagua (PR) & 9,94 & 10,51 & 5,83 & 4,14 & 3,51 \\
\hline & Vitória (ES) & 9,43 & 9,81 & 11,58 & 5,88 & 4,05 \\
\hline & Outros & 0,73 & 4,97 & 3,37 & 1,94 & 1,77 \\
\hline \multirow{3}{*}{$\mathrm{GO}$} & \begin{tabular}{|l} 
Santos (SP) \\
\end{tabular} & \begin{tabular}{|l|}
64,48 \\
\end{tabular} & 66,90 & 57,37 & 56,95 & 49,95 \\
\hline & Vitória (ES) & 30,45 & 26,34 & 33,25 & 30,20 & 39,36 \\
\hline & Imbituba (SC) & - & 0,26 & - & 2,46 & 3,31 \\
\hline UF & \begin{tabular}{|lll} 
Porto (UF do \\
porto)
\end{tabular} & 2013 & 2014 & 2015 & 2016 & 2017 \\
\hline \multirow{3}{*}{ GO } & Paranagua (PR) & 1,58 & 4,15 & 5,43 & 5,30 & 4,25 \\
\hline & $\begin{array}{l}\text { São Francisco do } \\
\text { Sul (SC) }\end{array}$ & 2,64 & 2,32 & 3,31 & 2,26 & 2,11 \\
\hline & Outros & 0,85 & 0,03 & 0,64 & 2,83 & 1,02 \\
\hline \multirow{6}{*}{ MS } & Paranagua (PR) & 40,78 & 37,95 & 32,40 & 34,40 & 37,11 \\
\hline & Santos (SP) & 27,82 & 21,20 & 30,43 & 31,37 & 24,58 \\
\hline & $\begin{array}{l}\text { São Francisco do } \\
\text { Sul (SC) }\end{array}$ & 30,99 & 40,29 & 35 & 29,60 & 30,49 \\
\hline & Murtinho (MS) & - & - & - & 1,58 & 5,05 \\
\hline & Rio Grande(RS) & 0,41 & 0,40 & 2,11 & 2,47 & 2,48 \\
\hline & Outros & - & 0,16 & 0,06 & 0,58 & 0,29 \\
\hline
\end{tabular}

Fonte: Aliceweb/Mdic

Considerando-se o município de Sorriso (MT), um dos principais produtores de soja do país, temos que sua distância até Barcarena é semelhante à distância até Santos, aproximadamente $2000 \mathrm{~km}$. No entanto, a grande vantagem na utilização do porto de Barcarena diz respeito ao fato de que metade do trajeto pode ser realizado por pela hidrovia do Rio Tapajós. Em 2014 foi inaugurado em Miritituba no oeste do Pará, a primeira estação de transbordo de cargas rodo-hidroviário do município, sendo esta financiada pela Bunge ${ }^{2}$ em parceria com a Amaggi. A partir disso outras estações foram inauguradas, formando o complexo de transbordo de Miritituba, sendo esse o grande alimentador do complexo portuário de Barcarena. Cabe ressaltar que também se encontram a margem do rio Tapajós, os portos de Santarém e Itaituba. O grau do sucesso dos novos empreendimentos logísticos está interligado as condições da BR-163, pois essa rodovia é o caminho da região produtora do Mato Grosso até o município de Miritituba. Deve ser destacada, a participação da iniciativa privada, que investiu 700 milhões de reais

\footnotetext{
${ }^{2}$ Ver http://www.bunge.com.br/Imprensa/Noticia.aspx?id=636
} 
na criação da estação de transbordo em Miritituba e no aumento da capacidade de operação do complexo portuário de Vila do Conde, em Barcarena.

Em relação a BR-364, além de ser importante no escoamento rodoviário para o porto de Santos, ela também pode ser utilizada para escoamento pelo Norte, ligando as regiões produtoras do Mato Grosso a Porto Velho (RO), principalmente a microrregião Parecis do Mato Grosso. A grande vantagem consiste que a partir de Porto Velho o escoamento pode ser feito através da hidrovia da madeira, pelo rio homônimo e depois pelo rio Amazonas, até a cidade de Itacoatiara (AM), onde a soja é exportada pelo complexo portuário de Itacoatiara. A distância de Sapezal (MT) até Itacoatiara é semelhante à distância até Santos, mas assim como no trajeto Sorriso Barcarena, podese utilizar a hidrovia em metade do trajeto até Itacoatiara. Cabe ressaltar ainda que existe a possibilidade de envio pelo rio Madeira a partir de Porto Velho para o porto de Santarém.

O estado de conservação da BR-364 no trecho entre o oeste do Mato Grosso e Porto Velho é um constante motivo de preocupação, segundo o DNIT em 2016 esse trecho estava com toda a extensão pavimentada. No entanto o pavimento foi classificado como regular, com relatos de muitos buracos principalmente durante a época de maiores índices pluviométricos. A geometria da via que analisa característica como a existência de acostamento, traçado da infraestrutura também foi considerada ruim na extensão de Rondônia e regular em Mato Grosso. Apenas um pequeno trecho é duplicado, prejudicando o tráfego pela rodovia e aumentando o número de acidentes.

Apesar das dificuldades estruturais podemos destacar a progressiva perda de importância relativa dos portos do sul e sudeste, com destaque para os portos de Paranaguá e Vitória, no escoamento da soja oriunda do Mato Grosso. Evidenciando assim um deslocamento do escoamento de soja mato-grossense dos portos do sul e sudeste para os portos do Norte, conforme tabela 4. Para não permitir uma interpretação equivocada é essencial informar que os portos do sul e sudeste movimentam volumes superiores de soja em relação ao passado, até mesmo devido a expansão da produção e exportação nessas regiões. Podemos destacar também que, exceto o Mato Grosso, os outros estados da região centro oeste seguem escoando suas produções pelos portos do sul e sudeste na mesma proporção durante todo o período analisado. Nesse ponto é importante ressaltar a importância do frete marítimo. A viagem originada dos portos do norte para a China, principal demandante da soja, são mais longas em relação a partidas originadas dos portos do sul e sudeste, aumentando seu custo em relação a esses portos, portanto a maior rentabilidade da atividade associada a utilização dos portos do arco norte, possuem relação estreita com o comportamento do preço do frete marítimo, sendo necessário que a redução no custo logístico interno supere a diferença do frete marítimo (SALIN, 2015).

O porto de Santos ainda constitui-se como sendo o principal ponto de exportação da soja do Mato Grosso. O trajeto com mais de 2 mil km é realizado pela BR 364, que em sua maior parte não é duplicada. Uma opção para o escoamento até Santos são os terminais ferroviários no sudeste do estado, próximos a fronteira com Goiás e Mato Grosso do Sul, localizados nas cidades de Rondonópolis e Alto Taquari e operados pela América Latina Logística Malha Norte S.A. Segundo o anuário estatístico das ferrovias, em 
2016, cerca de 7,84 milhões de toneladas de soja e farelo foram transportados por essa ferrovia, contando todos os terminais de transbordo existentes em seu trajeto. Além dos dois citados, o outro terminal é localizado em Chapadão do Sul (MS). Podemos notar que a utilização do modal rodoferroviário segue uma trajetória de crescimento suave, ao analisar a série histórica de dados no gráfico 6. O aumento de 600 mil toneladas transportadas pela Malha Norte entre 2016 e 2011 é bem menor do que a variação no volume de soja e farelo oriundos do Mato Grosso escoado por Santos, que nesse mesmo período ultrapassou os três milhões de toneladas sinalizando que o volume exportado por Mato Grosso em Santos cresce mais rapidamente que o volume embarcado na ferrovia.

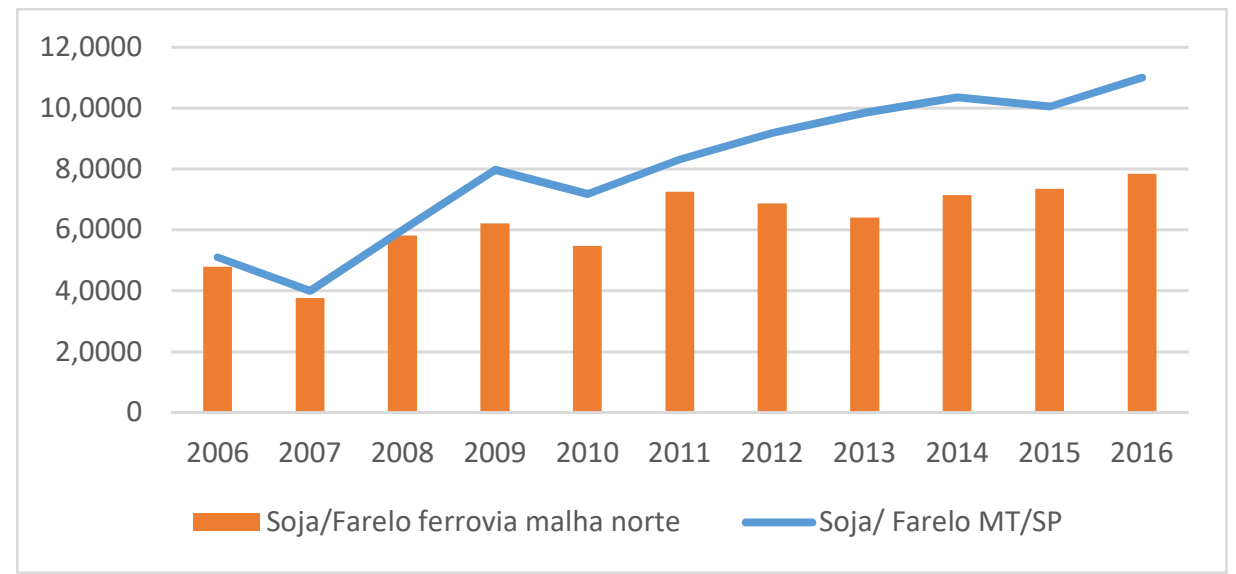

Gráfico 6 - Volume de Soja e farelo transportados na malha norte x volume de soja e farelo de MT escoado por Santos

Fonte: ANTT e MDIC

Não podemos desconsiderar o peso do frete interno, das regiões produtoras do Mato Grosso até o terminal de Rondonópolis, uma vez que o estado possui uma área territorial bastante extensa, assim o trajeto da origem até o transbordo pode implicar em longas distâncias a serem percorridas pelas rodovias mal conservadas do estado.

O panorama observado na região sul é bastante diferente daquele observado no Centro Oeste. Os grandes produtores de soja, Paraná e Rio Grande do Sul escoam quase que a totalidade de sua produção por portos internos ou próximos ao Estado, notadamente: Paranaguá (PR), São Francisco do Sul (SC) e Rio Grande (RS). Esse panorama é semelhante aquele observado na Argentina, onde a distância a ser percorrida para chegar até os portos é relativamente pequena, principalmente em relação ao centro oeste brasileiro ou ao meio oeste dos Estados Unidos. Cabe ressaltar ainda a maior capilaridade da infraestrutura no sul do Brasil quando comparamos ao centro oeste. A densidade da malha rodoviária, tanto pavimentada quanto não pavimentada, é muito superior ao cerrado. No entanto, o estado de conservação e principalmente a capacidade dessas rodovias muitas vezes são fatores de ineficiência. 


\section{CONSIDERAÇÕES FINAIS}

Como exposto ao longo do texto o Mato Grosso tornou-se a partir dos anos inicias deste século a principal região produtora de soja do Brasil. Observou-se também que esse Estado possui deficiências de infraestrutura ainda mais intensas do que os outros produtores da oleaginosa no Brasil, de modo que o transporte rodoviário é ainda a principal alternativa para o escoamento da produção. Tais fatos associados a uma maior distância aos portos e as características da carga, onera sobremaneira seu custo logístico.

Assim, torna-se fundamental estabelecer uma agenda de pesquisa que possa compreender os custos de implantação e operação de projetos de infraestrutura que visem minorar o custo logístico total desse estado. Para tanto, requer-se um minucioso levantamento dos dados disponíveis no que concerne as rotas utilizadas e os custos associados ao transporte da produção dos municípios produtores aos portos de embarque para subsidiar a análise de um portfólio de possíveis projetos de infraestrutura a serem implementados. A partir desse ponto tornar-se-ia possível formular um modelo teórico que vise apontar os projetos de infraestrutura que iriam alcançar o menor custo total logístico ao longo do tempo. Esses modelos em geral envolvem a utilização de ferramentas estatísticas e de programação matemática conforme proposto por Branco et al. (2010).

A complexidade dessa tarefa é ainda maior quando levamos em consideração que somente o Mato Grosso possui uma área de aproximadamente $903.329,70$ km², sendo superior à soma das regiões Sul e Sudeste, exceto Minas Gerais (Portal Brasil, 2018).

\section{REFERÊNCIAS}

AGÊNCIA NACIONAL DE TRANSPORTES TERRESTES - ANTT. Anuário do Setor Ferroviário 2017. Disponivel

em:

<http://www.antt.gov.br/backend/galeria/arquivos/Ferroviario/PDF-Relatorio-

Executivo-Setor-Ferroviario-2017-ANTT.pdf>. Acesso em: 14 nov. 2017.

BRANCO, José Eduardo Holler, et al. Desenvolvimento de modelo matemático de otimização logística para o transporte multimodal de safras agrícolas pelo corredor centro-oeste. Universidade de São Paulo. São Paulo, jan. 2010.

BRUM, A. L.; HECK, C. R.; LEMES, C. L.; MÜLLER, P. K.: A economia mundial da soja: impactos na cadeia produtiva da oleaginosa no Rio Grande do Sul 1970-2000. Anais dos Congressos. XLIII Congresso da Sober em Ribeirão Preto. São Paulo, 2005.

CAMPOS, A. C. de; PAULA, N. de. A evolução da agropecuária brasileira nos anos 90. Indicadores Econômicos FEE, Porto Alegre, v. 29, n. 4, p. 177-199, fev. 2002.

CAMPOS, M.C. O papel do estado brasileiro na expansão do complexo da soja. XII Coloquio Internacional de Geocrítica. Bogotá, 2012.

CONFEDERAÇÃO NACIONAL DO TRANSPORTE - CNT. Entraves logísticos ao escoamento de soja e milho. Brasília: CNT, 2015. 
p. 37 - Logística de Transportes e Expansão da Produção de Soja no Centro Oeste

CORREA, V. H. C.; RAMOS, P. A precariedade do transporte rodoviário brasileiro para o escoamento da produção de soja do Centro-Oeste: situação e perspectivas. Revista de Economia e Sociologia Rural, Brasília, v. 48, n.2, abril/junho 2010.

DALL'AGNOL, Amélio. A Embrapa Soja no Contexto do Desenvolvimento da Soja no Brasil: Histórico e contribuições. 1. ed. Brasília: Embrapa, 2016.

DEPARTAMENTO NACIONAL DE INFRAESTRUTURA DE TRANSPORTES - DNIT. Sistema Nacional de Viação, Lei no 12. 379, de 6 de janeiro de 2011. Disponível em: <http://www.dnit.gov.br/sistema-nacional-de-viacao/sistema-nacional-de-viacao>.

Acesso em: 02 nov. 2017.

FLEURY, F. A infra-estrutura e os desafios logísticos das exportações brasileiras. Centro de Estudos em Logísticas (CEL), Instituto COPPEAD de Administração, Universidade Federal do Rio de Janeiro (UFRJ), 2005.

HIJJAR, M. F. Logística, soja e comércio internacional. Centro de Estudo em Logística. COPPEAD, UFRJ, Rio de Janeiro, 2004

HIRAKURI, M. H.; LAZZAROTTO, J.J. O Agronegócio da Soja nos Contextos Brasileiro e Mundial. Londrina: Embrapa, 2014.

INSTITUTO BRASILEIRO DE GEOGRAFIA E ESTATÍ́STICA - IBGE. Anuário Estatístico do Brasil. Rio de Janeiro: 1941/2016.

INSTITUTO MATO GROSSENSE DE ECONOMIA AGROPECUÁRIA - IMEA. Entendendo o mercado da soja. Workshop jornalismo agropecuário. Cuiabá, junho, 2015.

KUSSANO, M. R.; BATALHA M. O. Custos logísticos agroindustriais: avaliação do escoamento da soja em grão do Mato Grosso para o mercado externo. Revista Gestão e Produção, São Carlos, v. 19, n. 3, 2012.

MINISTÉRIO DA INDÚSTRIA, COMÉRCIO EXTERIOR E SERVIÇOS, MDIC. Sistema Alice Web. Disponível em: <http://aliceweb.mdic.gov.br/>. Acesso em 01 dez. 2017.

MINISTÉRIO DOS TRANSPORTES PORTOS E AVIAÇÃO CIVIL - MTPA. Anuário Estatístico de Transportes 2010-2016. Brasília, 2017.

PAULA, Sergio Roberto Lima de; FAVERET FILHO, Paulo de Sá Campello. Panorama do complexo soja. BNDES Setorial, Rio de Janeiro, n. 8, p. 119-152, set. 1998.

PONTES, H. L. B.; CARMO, B. B. T. do; PORTO, A. J. V. Problemas logísticos na exportação brasileira da soja em grão. Revista eletrônica Sistema e Gestão, v. 4, n. 2, p. 155-181, maio/agosto 2009.

SALIN, D. L. Soybean Transportation Guide: Brazil 2014. United States Departament of Agriculture, Agricultural Marketing Service. Julho, 2015.

SALIN, D. L. Soybean Transportation Guide: Brazil 2016. United States Departament of Agriculture, Agricultural Marketing Service. Maio, 2017.

TAVARES, C. E. C. Estimativa do escoamento das exportações do complexo soja e milho pelos portos nacionais. v. 1, Brasília, Conab, 2016. 
UNITED STATES DEPARTAMENT OF AGRICULTURE - USDA. Foreign Agricultural Service. Disponível em: <https://apps.fas.usda.gov/psdonline/app/index.html\#/app/advQuery>. Acesso em: 01 dez. 2017. 